\title{
School Administrators: Establishing Positive Relationships with Stakeholders
}

\author{
Dr. David E. Bartz \\ Professor Emeritus \\ Department of Educational Leadership \\ Eastern Illinois University \\ USA \\ Dr. Cliff Karnes \\ Chairperson \\ Department of Educational Leadership \\ Eastern Illinois University \\ USA
}

\begin{abstract}
It is essential that school administrators establish positive relationships with stakeholders that result in productive support and accomplishment of the goals they are expected to achieve. Holistically, positive and productive relationships are achieved by school administrators with stakeholders engaging in two-way or multiparty communications, active listening, giving encouragement and support, setting clear goals and expectations, explaining the "why" of goals and related tasks, providing feedback to stakeholders, and coaching to help stakeholders be their best. Specific areas that school administrators need to address in establishing positive and productive relationships are basic principles of positive psychology, communication skills, effectively utilizing diversity, social intelligence, empathy, vulnerability, outward mindset, and impressions management.
\end{abstract}

Keywords: school administrators, productive relationships, stakeholders

\subsection{Context}

"We're instinctively drawn to people who are modest, agreeable, polite, kind. . in short, to people who are genuinely likable" (Haden, 2018, p. 58).

Two factors for being an effective school administrator that have been identified for decades are: (1) accomplishing goals (results) and (2) building positive relationships that influence stakeholders to help achieve these goals. These two factors interact such that one complements the other. In essence, one does not exist without the incorporation of the other. This article focuses on the building positive relationships factor. School administrators are reminded that their overall behaviors should be guided by these two questions: (1) Do I focus on what matters most for students' learning? and (2) Do I make a difference daily for our students? (National Policy Board for Educational Administration, 2015).

Holistically, positive relationship building behaviors with stakeholders are represented by school administrators engaging in two-way or multi-party communications, active listening, giving encouragement and support, setting clear goals and expectations, explaining the "why" of goals and related tasks, providing feedback, and coaching to help others be their best (Hersey, Blanchard, \& Johnson, 2013). Shannon (as cited in Shellenbarger, 2018) advocates "to spread positivity by showing genuine interest in others" in the context of school administrators fostering positive relationships with stakeholders (p. A15). Kaplan and Marsh (2018) advocate that building positive relationships helps school administrators to "connect to the power of other people" (p. 67). Specific areas presented in this article for school administrators to utilize in establishing positive relationships with stakeholders are: (a) basic principles of positive psychology, (b) communication skills, (c) effectively utilizing diversity, (d) social intelligence, (e) empathy, (f) vulnerability, (g) outward mindset, and (h) impressions management. 


\subsection{Basic Principles of Positive Psychology}

The positive psychology movement offers school administrators reference points for reflecting on how they perceive themselves and work with staff and other stakeholders to create the most effective culture and climate for establishing positive relationships. According to Seligman (2011), who coined the term in 1998, positive psychology is the scientific study of the positive aspects of the human experience. It examines the strengths that enable school administrators to thrive and reach their full potential. Positive psychology focuses on the wellbeing, satisfaction, and positive aspects of mental health, as opposed to psychology that has traditionally focused on negative factors such as the weaknesses and mental illnesses of people. Major aspects of positive psychology applicable to school administrators maximizing job performance and building positive relationships with stakeholders are: (a) embracing the challenges of the job with a passion and being energized to work with others to successfully meet them, (b) learning from setbacks and adversity at work and not being discouraged, (c) engaging stakeholders in developing a district's and schools' goals and taking actions to accomplish them, (d) viewing staff and other stakeholders as the district's and schools' major asset for improving education for students, (e) helping staff and other stakeholders to be their best, (f) focusing on building positive and productive relationships with others, ( $\mathrm{g}$ ) finding fulfillment and excitement in being creative to collaboratively solve problems, and (h) looking beyond oneself to help stakeholders find satisfaction and enjoyment in their efforts to benefit students (Seligman, 2011; Seligman, 2006; Seligman, 2002; Grenville-Cleave, 2012).

\subsection{Communication Skills}

Effective communication is the process of transferring information and understanding from the school administrator to stakeholders and vice-versa. Two-way communication works best when school administrators "check for understanding" to ensure stakeholders have a common interpretation of the key elements being discussed. Both verbal and nonverbal skills play an important role in effective communication and establishing common understanding. Examples of nonverbal communication factors are: (a) body movement such as gestures, (b) how and where the school administrator is positioned (e.g., standing, sitting behind the desk, at a table, sideby-side, or in a chair facing the stakeholders) while interacting with others, (c) facial expressions (e.g., smile or frown), (d) psychological reactions such as blushing or paleness, and (e) eye contact.

Effective verbal communication is more than merely words. Pitch and tone, use of pauses, the context in which a statement is made, and the use of silence are examples of variables involved in meaningful verbal communication. Attending, reflecting, exploring, self-disclosure, and acceptance are essential verbal skills needed by school administrators to build positive relationships with stakeholders.

1. Attending: The school administrator expresses interest in what the stakeholder is expressing and feeling by:

- Physical attending: general posture, facing the stakeholder, maintaining eye contact, standing or sitting in a relaxed rather than a tense position, and having a pleasant facial expression.

- Mental attending: paying close attention to the stakeholder's verbal and nonverbal behaviors and relating what is being communicated to what has previously been discussed (this is "in-the-moment" mindfulness).

2. Reflecting: The school administrator projects a sincere desire to understand the stakeholder's situation and feelings by reviewing what the stakeholder has expressed, clarifying it, and periodically summarizing to make sure that the meaning and intent have been correctly understood by both parties.

3. Exploring: The school administrator continually examines and probes what the stakeholder is stating to identify specific concerns or problems. If an incomplete explanation or contradictory information is given, the school administrator asks questions in order to obtain more information and prompt the stakeholder to provide an "in-depth" explanation.

4. Self-disclosure: The school administrator shares thoughts and information with the stakeholder related to the topic at hand based on the school administrator's background experiences. This provides a supportive and constructive relationship concerning what the stakeholder has communicated and builds rapport.

5. Acceptance: The school administrator shows appreciation and respect for the stakeholder as a fellow human being and does not attack the individual's dignity. Respect for differing opinions is critical for school administrators' professional growth.

The school administrator must determine when to use each of these five communication skills in order to increase the effectiveness of the communications with stakeholders in building positive and productive relationships (Bartz, 2017). 


\subsection{Effectively Utilizing Diversity ${ }^{I}$}

As used here, diversity means:

- Understanding that there are personal differences among stakeholders and these differences, if properly managed, are an asset to tasks being accomplished more efficiently and effectively;

- Understanding that differences among stakeholders do not negate positive relationships but, because of the uniqueness of these differences, offer numerous points for creating positive relationships;

- Understanding that differences among stakeholders create a more expanded environment with a broader range of perspectives and attributes;

- Capturing the richness of differences of a stakeholder and harnessing them to enable the school or district to make better decisions in improving student learning;

- Understanding that people are different and if properly nurtured and cultivated, these differences are a positive force;

- Striving to create a culture that is heterogeneous and utilizes maximum participation of all stakeholders to their full potential; and

- Demonstrating mutual respect, acceptance of others, and the desire to work for the common good of a school or district for the betterment of students.

Ultimately, school administrators must be able to interact and work effectively with others whom they may initially view as "different" for a variety of reasons. The effective use of diversity helps to build stakeholders' commitment and identity within the school or district. Diversity's goal is inclusion. This inclusion of stakeholders from various perspectives must be authentic and meaningfully involve them in the decision-making processes to address the issues at hand. "Tokenism" is not only ineffective but, quite frankly, offensive. Inclusion needs to focus on building positive relationships through collaborative problem solving and striving to prompt innovative outcomes that maximize the human capital of stakeholders.

\subsection{Effective Group Processes in the Context of Diversity}

Effective groups generally have at least three major components: (1) purpose, (2) effective use of human capital (people), and (3) operating in a comprehensive manner such that diversity is viewed as being inclusive in the context of assuring participation by a variety of members to maximize the various perspectives brought to the table. To maximize the impact of diversity and collaboration when working with groups, school administrators need to incorporate these effective group practices to create positive relationships and achieve goals:

- Make sure all stakeholders have the opportunity for equal time to express their views and give input;

- Create an environment that encourages participation and prompts participants to feel free to give differing viewpoints;

- Strive to create a climate of respect;

- Understand that good ideas can come from anyone, regardless of a stakeholder's formal position or uniqueness;

- Create an environment of authenticity and free dialogue;

- "De-individualize" group members so that their personal identity does not prevent merging themselves into a cohesive unit as an effective work group;

- Strive to create group drive (energy, enthusiasm, and strong commitment to working collaboratively with others to achieve the group's goals);

- Clarify members' roles, eliminating competition within the group, and facilitating early on the establishment of a plan for how the group will operate on the specific tasks needed to accomplish goals (including a timeline); and

- Act as a gatekeeper to make sure the group stays on course, prevent certain stakeholders from dominating, block antagonism and aggression, and seek input from members apprehensive to contribute (Bass \& Bass, 2008, pp. 756-785).

Lencioni's (2002) Five Dysfunctions of a Team also gives guidance for school administrators for maximizing diversity's effectiveness with groups to build positive relationships and successfully accomplish goals. Specifically, efforts should focus on the following beliefs:

- Members having enough trust in each other to openly share past experiences and current thoughts,

- Removal of the fear of conflict so members do not "hold back" from participating,

- Gaining commitment so members believe in the purpose and goals to be achieved and fully support them, 
- A willingness for members and the group as a whole to be accountable for their actions and goals achieved, and - An unwavering belief in the group members' abilities to achieve the goals of the group even if it could have a negative impact on how they are personally viewed (Lencioni, 2002, pp.195-220).

It is important to note that there is often a need for group members to have a social dimension met in order to enhance identity and a passion to be an ongoing motivated group member and contribute to positive relationships. This social dimension is sometimes referred to as the group's emotional intelligence (Druskat \& Wolff, 2013). Activities that prompt meaningful social interactions among group members to enjoy the company of one another through meals and break times are important to enhancing interpersonal understanding, better appreciating others' perspectives, and developing positive relationships. While such activities may seem to counter the need to accomplish goals, in the long run they will enhance goal attainment through positive intergroup relationships.

\subsection{Social Intelligence $e^{2}$}

Social intelligence is defined as a set of interpersonal competencies that inspire stakeholders to support the school administrator's efforts and goals to be accomplished through establishing positive relationships (Goleman and Boyatzis, 2013). School administrators must develop a genuine interest in developing the skills needed for causing positive feelings in stakeholders and, thus, building positive relationships.

Tredgold (2018) opines - that in the context of school administrators making connections - building positive relationships with others to "be mindful to the people who are around you and connect to them. Be generous with your attention. As you make these connections, your team [stakeholders] will want to work harder for you" (5-2, p. 1).

Social intelligence advocates that being attuned to the moods of stakeholders affects the school administrator's performance as well as that of the stakeholders. In essence, a school administrator exhibiting a very caring mood prompts the stakeholder with whom the interaction is taking place to be on the same brain frequency as him/her. Once this interconnectedness takes place, a positive relationship exists, and the stakeholder is more inclined to behave in a positive manner and want to support and work to achieve the goals for which the school administrator is responsible. Some school administrators have more natural talent in the area of social intelligence than others. Nevertheless, social intelligence can be learned.

Basic social intelligence skills are: (a) attunement; (b) organizational awareness; (c) influence; (d) developing others; (e) teamwork; (f) inspiration; (g) situational awareness; (h) presence; (i) authenticity; (j) clarity; and (k) knowledge of social roles, rules, and scripts (Goleman \& Boyatzis, 2013; Riggio, 2014).

- Attunement means listening carefully to determine how stakeholders feel and connecting with their moods. This also includes positive communications through non-verbal behaviors.

- Organizational Awareness means understanding social networks, being cognizant of their apparent intended meaning - as well as unspoken norms - and appreciating the culture and values of the general organizational and work environments.

- Influence is getting support from stakeholders by appealing to their interests, thereby persuading them to be engaged in discussions and openly exposing their thoughts. This is especially important to develop in the staff members and other stakeholders who are most respected by their peers.

- Developing Others means demonstrating interest and providing meaningful feedback that is helpful to stakeholders. This involves the commitment of personal time and energy through activities such as compassionate coaching and mentoring.

- Teamwork involves providing psychological support for stakeholders on teams, committees or in group activities and creating a cooperative spirit in which everyone participates for the common good. This includes providing support and demonstrating a personal interest in each stakeholder.

- Inspiration is communicating a compelling vision, building pride, establishing a positive emotional tone, and motivating stakeholders to do their best work and foster positive relationships among others.

- Situational Awareness means utilizing skills in observing and understanding the context of a situation and the ways it impacts or shapes the behaviors of stakeholders.

- Presence is the overall impression or "total message" sent to stakeholders by the school administrators. (Presence involves the inferences that stakeholders make about a school administrator's character and competency based on the school administrator's behaviors which they observe.) 
- Authenticity is the extent to which stakeholders perceive the school administrator as acting from honest and ethical motives, the extent to which stakeholders sense that the school administrator's behaviors are congruent with personal values, and that the school administrator is "playing it straight."

- Clarity is the skill in which the school administrator expresses ideas clearly, effectively, and with impact. It includes paraphrasing, semantic flexibility, skillful use of language, proficient use of metaphors, figures of speech, and explaining things clearly and concisely.

- Knowledge of Social Roles, Rules, and Scripts means that the school administrator understands the informal rules or "norms" that govern social interaction in a setting. It is "knowing how to play the game" of social interaction and being viewed as socially sophisticated.

\subsection{Empathy ${ }^{3}$}

Empathy is a school administrator's skill set for sensing and relating to the feelings, thoughts, experiences, and general situation of stakeholders who are experiencing emotional difficulties and challenges. It is akin to the school administrator putting oneself in the position of the other person and attempting to see the situation through that person's eyes (Krznaric, 2014). The school administrator's skills in focusing and paying close attention to the feelings and the situations of stakeholders are essential in being able to effectively apply empathy.

Martinuzzi (2009a) believes that empathy feeds positive relationships between school administrators and stakeholders and "keeps relationships running smoothly" (p. 20). School administrators should not confuse empathy with sympathy. Sympathy emphasizes one's display of sorrow or pity for the hardships encountered by another person and does not involve trying to understand the other person's emotions or perspectives (Krznaric, 2014). Empathy is feeling with someone else, whereas sympathy is feeling bad for someone else (Pink, 2006).

Regarding empathy, Martinuzzi (2009b) indicates that "it's a soft, sometimes abstract tool in a leader's [school administrator's] toolkit that can lead to hard, tangible results" (p. 2). Empathy does not require the school administrator to agree with a stakeholder's perspective, but it does require acknowledging and attempting to understand the thoughts, feelings, and concerns of a stakeholder. In order to effectively apply empathy, school administrators need to be willing to leave their comfort zone of personal values and beliefs and step into the shoes of the other person to perceive the situation from that stakeholder's perspective. Empathetic school administrators must be capable of understanding what is transpiring in the stakeholder's life through sensing and relating to the feelings, thoughts, and general perceptions of the stakeholder encountering emotional difficulties (Holt, Marques, $\mathrm{Hu}, \&$ Wood, 2017).

Brown (2014a) explains empathy as "A driver of connection, it is a bonding agent that strengthens relationships. It is one human being connecting with another, acknowledging a person's circumstance without diminishing or rationalizing it. Empathy is an acknowledgement without judgment" (p. 1). When compared with some of the traditional school administrators of past years, the present day enlightened school administrator realizes the importance of being able to mentally connect with stakeholders in order to better understand what inspires and motivates them. Empathy aids in this pursuit.

Goleman (2017) identifies three distinct types of empathy relevant to school administrators: (1) cognitive empathy, (2) emotional empathy, and (3) empathetic concern. Cognitive empathy is the school administrator's skills in understanding perspectives, mental state, and feelings experienced within a stakeholder's frame of reference. As indicated by Goleman (2017), "exercising cognitive empathy requires leaders [school administrators] to think about feelings rather than to feel them directly" (p. 4). Cognitive empathy requires school administrators to be self-aware by understanding their own feelings in order to comprehend the feelings of stakeholders. To effectively apply cognitive empathy, a school administrator needs to meaningfully explain her/his feelings about the situation to the stakeholder in a concerning manner in order to create a bond and positive relationship. Curiosity and inquisitiveness aid school administrators in effectively utilizing cognitive empathy.

Emotional empathy is represented by school administrators responding with specifically appropriate emotions and feelings to a stakeholder's mental state and being able to identify as also having been affected by what the stakeholder is experiencing. Effective emotional empathy serves school administrators well in the roles of coaching, mentoring, and helping stakeholders work through difficult emotional times. 
Emotional empathy is dependent upon the school administrator combining two types of focused attention: (1) conscious and deliberate concentration on the stakeholder's feelings and the specifics of the situation; and (2) awareness of facial expressions, voice, and other signs of concern or distress sent off by the stakeholder (Goleman, 2017).

Empathetic concern is used by school administrators for more acute emotional difficulties of a stakeholder. It is the school administrator's skills at sensing what the stakeholder needs and displaying compassion in response to that person's suffering and difficulties. Bloom (2016) supports the use of compassion in this context if compassion is characterized by feelings of warmth, concern and care for others, as well as a strong motivator to improve others' well-being (p. 138). Compassion requires a school administrator to personally connect with a stakeholder's suffering and distress with authentic empathetic concern. The school administrator must sincerely value the stakeholder's well-being. School administrators are cautioned, though, regarding possible compassion fatigue when engaging in empathy concern for an extended time period. Compassion fatigue means that dealing with the stakeholder's situation begins to take a toll on the school administrator's ability to perform effectively.

School administrators often become aware of stakeholders or colleagues experiencing difficulties through observing their behavior and emotional state and concluding that something is "wrong." Some situations requiring empathy for stakeholders by the school administrator are easier to identify, such as a death in the family. Other situations, such as one prompted by a stakeholder spending huge amounts of time away from work as a caregiver, are more difficult to identify and take longer to do so.

When a stakeholder's behavior is in question because of emotional issues from work, personal life, or other situations, the school administrator may initially believe it is necessary to be aggressive and make very clear to the stakeholder what is acceptable and unacceptable behavior. In these situations, some school administrators may even react with anger. This approach erodes trust, loyalty, and the stakeholder's motivation to work collaboratively with the school administrator. In the long run, taking a more compassionate and sincere approach to conversations with such a stakeholder, with the purpose of determining the cause of the behavior problem, is the best approach (Seppala, 2017). Utilizing empathy in the context presented here, the school administrator's objectives are: (a) assuring there is a positive relationship with the stakeholder, (b) "digging in" through the effective use of the empathy process to determine the heart of the problem, and (c) prompting the stakeholder's behavior to be more productive.

Martinuzzi (2009b) offers these suggestions for school administrators as tools to aid in effectively utilizing empathy: (a) truly listen with your ears, eyes, and heart to get context clues for better understanding; (b) get the person to open up and share, which might take several conversations; (c) guard against interrupting the stakeholder in conversations; (d) give undivided attention and focus to the stakeholder; (e) take a sincere personal interest in the stakeholder; and (f) create a sense of "connectedness" by demonstrating that you genuinely care. The ability to empathize is not a fixed or limited quantity in a school administrator. Krznaric (2014) states that "there is overwhelming agreement among the experts that our personal empathy quota is not fixed: we can develop our empathetic potential throughout our lives" (p. 27).

Effective communication is the foundation on which rapport, trust, and meaningful exchange of information occurs in order for the school administrator to effectively utilize empathy skills with a stakeholder. The school administrator must consistently check for understanding to reinforce and clarify the specifics of the situation and all key factors associated with it. An example of checking for understanding is a question such as: "Let me make sure I understand what you're saying is . . .?" (Zenger \& Folkman, 2017, p. 32). School administrators also need to be aware of the 93 Percent Rule with respect to communication. The 93 Percent Rule indicates that the words stated accounts for only 7 percent of the total message people receive, and the remaining 93 percent of the message communicated comes from factors such as tone of voice and body language (Jacobsen, 2013).

\subsection{Vulnerability ${ }^{4}$}

It is important for school administrators to be unafraid to showcase their vulnerabilities in the quest to build positive and productive relationships with stakeholders. To be sure, there are plenty of situations in which going out of the way to project weakness is not a good thing, but there are also many instances where admitting vulnerability will help engender trust and buy-in among stakeholders. Demonstrating vulnerability is relatable-it shows that the school administrator is human and not simply a "know it all" (Kalman, 2017, p.3). 
Vulnerability means school administrators are exposing their uncertainties and taking emotional risks (Krznaric, 2014). A school administrator shows vulnerability by being open to input and feedback from stakeholders, even if such information is critical of the school administrator's opinions and actions. This is a challenge to many administrators, due to their own insecurities. It means that the school administrator encourages stakeholders to speak out and welcomes their comments when they are contrary to the school administrator's position, and even communicating that the school administrator could be wrong regarding a particular situation.

Vulnerability is shown by school administrators acknowledging that they do not have the answers to every question or solutions to every problem. Stibel (2017) indicates that school administrators need to admit what they do not understand and be willing to solicit assistance from stakeholders in order to grow and be more confident. A school administrator who displays vulnerability does not advocate submission but has the courage to honestly share doubts, feelings, and apprehensions with stakeholders (Seppala, 2014). Mistakes are inevitable, and school administrators should admit and "own up to them." Owning a mistake includes four key concepts: (1) giving oneself room to fail, (2) apologizing sincerely and soon if appropriate, (3) making amends if relationships with stakeholders occurred, and (4) psychologically letting the mistake go and moving on (Berman \& Bernard, 2018). As with many leadership behaviors, the key to the effective application of vulnerability is knowing when, where, and how to be both in control and vulnerable.

Vulnerability is creating a climate that encourages stakeholders to share opinions, perceptions, and divergent views. When school administrators authentically display vulnerability, they foster innovation, confidence, trust, loyalty, creativity, and a sense of connectedness among and between stakeholders and themselves. Martinuzzi (2009a) stresses that authenticity is the application of "candor and the avoidance of all deception" by school administrators when interacting with stakeholders (p. 8). Martinuzzi also indicates that authenticity implies a steadfast commitment to honesty and truthfulness.

Many school administrators adhere to the belief that they should keep a safe emotional distance from stakeholders and exude the use of authority regarding what needs to be done and how to do it. Some people may think that vulnerability shows weakness and indecisiveness on the part of the school administrator. School administrators adhering to this belief often use the power of their position to cause staff and other stakeholders to get what they want when differences or disagreements arise. School administrators adhering to keeping "emotional distance" and using authority and power to cause stakeholders to act need to reassess their mode of operation and consider using vulnerability. If properly applied, the results of vulnerability will be rewarding for them and stakeholders, and productivity will increase.

It takes courage and persistence — as well as confidence, positive self-esteem, and time - for school administrators to establish the perception of their vulnerabilities among stakeholders and others. Sometimes school administrators must consciously put aside facades they have built up over time in order to be more likely perceived as being vulnerable and open to differences of opinions and criticism. The pursuit of vulnerability by school administrators must be authentic and real, or stakeholders will view the efforts as contrived and phony.

School administrators who adhere to the servant-leader approach often are more adept regarding the use of vulnerability. A servant-leader shares power, puts the needs of stakeholders first, and helps people develop to their maximum potential. School administrators adhering to the servant-leader philosophy understand that staff and other stakeholders hunger for appreciation and make sure they provide such feedback (Martinuzzi, 2009a).

Confident school administrators are often more likely to be willing to display vulnerability than those who are insecure. Three tools that help build confidence in school administrators are: (1) exuding a positive attitude through actions and behaviors, (2) anticipating and being well prepared for what is likely to come next, and (3) feeling comfortable in reassuring stakeholders to boost their self-confidence (Berman \& Bernard, 2018). School administrators who are initially reluctant to expose themselves through vulnerability should phase into it, starting with small increments of one or two behaviors. Assuming this leads to positive results, school administrators can then expand progressively by continuing to add additional behaviors.

Effectively displaying vulnerability by the school administrator fosters trustworthiness, authenticity, courage, innovation, creativity, loyalty, and opportunities for stakeholders and oneself to grow and develop. Vulnerability can be a huge asset for any administrator wanting support from staff. In a study of CEOs over a decade, Bryant (2017) identified trustworthiness as the most important quality of effective leaders. 
Brown (2014b) indicates that a school administrator effectively displaying vulnerability to a stakeholder creates a strong social connection - a sense of "oneness" between the stakeholders and school administrator that, coupled with authenticity, is a powerful human connector.

\subsection{Outward Mindset ${ }^{5}$}

School administrators need to have an outward mindset to most effectively create positive relationships with stakeholders. As used here, mindset is the way people see and regard the world-how they see others, circumstances, challenges, opportunities, and obligations (The Arbinger Institute, 2016). This includes school administrators helping stakeholders be their best at fostering positive relationships and making substantial contributions to goal attainment. An outward mindset represents a focus on the impact a school administrator has on being inclusive of stakeholders, as opposed to being "self-focused" and promoting oneself, often at the expense of others. (Table 1 presents comparisons between the inward and outward mindset for school administrators.) The outward mindset has some similarity to Dweck's (2016) growth mindset which advocates change, innovation, and positivity in the context of developing new ideas. A major difference, though, is that the outward mindset's focus is almost always on others, whereas Dweck's growth mindset focuses more on the individual. With respect to the outward mindset, school administrators prompt stakeholders not to focus on themselves and their vested interests, but rather to work for the common good of all people involved, develop positive relationships, be productive, and achieve goals. Other specific attributes of the outward mindset are:

- Fostering a climate in which stakeholders are fully engaged and have a sense of responsibility;

- Working collaboratively with stakeholders to solicit their input so as to maximize their unique perspectives and then striving to develop the best collective solutions to problems;

- Creating an environment in which stakeholders develop a committed behavior collectively with others to solve problems;

- Considering the needs and wants of stakeholders to foster satisfaction and motivation in them;

- Bonding with stakeholders through establishing positive relationships to foster cooperation; and

- Viewing challenges to the school administrator's perspectives as positive, likely making the school administrator more productive and hence enhancing solutions for problem solving.

Table 1 Comparing Inward and Outward Mindsets for School Administrators Toward Staff and Others

\begin{tabular}{|c|c|}
\hline Inward Mindset & Outward Mindset \\
\hline 1. Strives to control people & $\begin{array}{l}\text { 1. Strives to cause staff and others to be fully } \\
\text { responsible and engaged in work }\end{array}$ \\
\hline $\begin{array}{l}\text { 2. Often blames others when things go } \\
\text { wrong }\end{array}$ & $\begin{array}{l}\text { 2. Takes responsibility for actions of oneself } \\
\text { and staff in the work environment }\end{array}$ \\
\hline 3. Is narcissistic & 3. Displays modesty toward staff and others \\
\hline 4. Consistently defends one's position & $\begin{array}{l}\text { 4. Works collaboratively with staff to solicit } \\
\text { their opinions and collectively develop the } \\
\text { best solutions for problems }\end{array}$ \\
\hline $\begin{array}{l}\text { 5. Has interactions with staff and others } \\
\text { that focus on protecting oneself }\end{array}$ & $\begin{array}{l}\text { 5. Has interactions with staff and others that } \\
\text { focus on building positive relationships } \\
\text { with and among people }\end{array}$ \\
\hline $\begin{array}{l}\text { 6. Uses behaviors that sometimes try to } \\
\text { manipulate staff and others in an attempt } \\
\text { to improve one's own image }\end{array}$ & $\begin{array}{l}\text { 6. Strives to facilitate "committed behaviors" } \\
\text { collectively with staff and others to improve } \\
\text { work produced and achieve goals }\end{array}$ \\
\hline $\begin{array}{l}\text { 7. Shows minimal regard for how to create } \\
\text { "collective results" among staff and } \\
\text { others }\end{array}$ & $\begin{array}{l}\text { 7. Is motivated about how to work with staff } \\
\text { and others collaboratively and for others } \\
\text { to collaborate with each other and oneself }\end{array}$ \\
\hline
\end{tabular}




\begin{tabular}{|c|c|}
\hline & \\
\hline Inward Mindset & \\
\hline 8. Views staff and others in a context as to & 8.
\end{tabular}

8. Focuses on the needs and challenges of staff and how they can help oneself achieve goals

9. Assumes that to simply change one's behavior is the best way to enhance the work productivity of staff and others

10. Focuses on how to make oneself "look good" for work produced, even at the expense of staff and others

11. Often creates competition between staff and causes them to work independently of each other

12. Focuses mainly on the job responsibilities of oneself

13. Focuses on getting the work "out the door" with little concern for its benefits

14. Is inclined to step in, take over, and direct the work of staff and others when not pleased

15. Creates conflict that keeps staff embattled with each other (divide and conquer for control)

16. Focuses on personal and professional goals and behaviors to protect and advance oneself

17. Advances one's own agenda at the expense of staff

18. Identifies what can be taken from others to achieve objectives for oneself

18. Identifies what can be given to help staff and others successfully achieve their work objectives 


\begin{tabular}{|l|l|}
\hline \multicolumn{1}{|c|}{ Inward Mindset } & \multicolumn{1}{c|}{ Outward Mindset } \\
\hline $\begin{array}{l}\text { 19. Oftentimes tries to control the behavior of } \\
\text { staff and others for self-benefit through } \\
\text { power, authority, and fear }\end{array}$ & $\begin{array}{l}\text { 19. Relinquishes power and authority to } \\
\text { empower staff's and others' abilities to be } \\
\text { responsible and accountable for their work } \\
\text { (Bartz, Thompson, \& Rice, 2017) }\end{array}$ \\
\hline
\end{tabular}

\subsection{Impressions Management ${ }^{6}$}

School administrators applying impressions management strive to persuade stakeholders with whom interactions occur to see ideas their way by creating a favorable and influential impression. This can be in one-to-one conversations or interacting with stakeholders in a group. Using the concept of mindfulness-active in-themoment awareness, sensitivity, and perspectives - aids school administrators in effectively using impressions management (Langer, 2017). Confidence, comfort level, and passionate enthusiasm are also beneficial. In preparation for attaining the desired outcome from an interaction, the school administrator needs to have her/his situation identity clearly focused on exactly what is the target of persuasion and desired impression to be created with a stakeholder to develop a positive relationship and achieve the desired outcome (Goffman, 1959). School administrators need to be adept at using reflection-in-action skills to adjust behavior, moment-by-moment, during interactions with stakeholders they are attempting to persuade.

The school administrator applying impressions management utilizes all available skills and resources such as personal appearance, mannerisms, body language, setting, and background information about the stakeholders with whom the interactions take place. While the school administrator attempts to control as many variables as possible when applying impressions management, it is imperative that his/her behaviors appear authentic rather than contrived or "phony."

Goffman (1959), the originator of the impressions management concept, believes school administrators create impressions when interacting with stakeholders through two types of expressions:

1. Expressions we "give." What the school administrator says, how one poses the situation, facial expressions, and intentionally controlling body language.

2. Expressions we "give off." Behaviors over which the school administrator is sometimes less cognizant and which are viewed as being inconsistent with what is stated because body language gives a different message.

A school administrator needs to effectively manage the expressions "we give off" so that verbal and nonverbal communication signals are congruent.

Four common impressions management strategies for school administrators are:

1. Ingratiation: (a) the art of gaining acceptance and prompting stakeholders to like them, usually in the context of an ulterior motive; (b) opinion conformity (agreeing with others); (c) flattery; and (d) cautiously guarding what is stated (e.g., choosing words carefully).

2. Supplication: attempting to gain sympathy and attention by revealing faults, tribulations, and the difficulty of the situation.

3. Self-promotion: (a) taking credit for events, (b) making others aware of accomplishments, and (c) presenting strengths to prove competency. (If congruency does not exist between the information presented and the stakeholder's perception of reality, this can be disastrous to a school administrator's effectiveness.)

4. Exemplification: (a) presenting one's moral worthiness; (b) displaying sincerity; (c) demonstrating dedication and responsibility to the issue at hand to show competency; and (d) advocating being the "right" person for the job/task at hand (Goffman, 1959; DeePak, 2014; Bolino, Klotz, \& Daniels, 2014).

It is essential for school administrators to be motivated and "psyched up" for persuading and influencing stakeholders in order to guide a conversation and achieve their desired predetermined image. Early in the conversation, the school administrator must quickly determine the gap between the stakeholder's position on her/his predetermined desired outcome and the administrator's position at that moment in time. As the conversation progresses, the gap should close. The school administrator showing the relevancy of his/her desired outcome to the other stakeholders is often key to gaining support. The school administrator should "back off" when it becomes apparent that the gap is not closing and the stakeholder is demonstrating alienation. 
After interacting with the stakeholder, the school administrator needs to objectively debrief the situation and ascertain the extent to which the desired image was achieved regarding the wanted outcome (Leary \& Kowalski, 1990).

Digital communications must also be considered as vehicles for impressions management. Most of the same strategies apply to digital interactions as do to face-to-face interactions. However, "conversations" conducted digitally are often non-continuous and not as "in-the-moment" as face-to-face situations. Hence, the school administrator has more time to contemplate responses, as does the stakeholder she/he is attempting to influence. Because digital communications are sometimes less formal than face-to-face, it is important that the school administrator not become lax or careless in preparation and attentiveness.

\subsection{Summary}

It is essential that school administrators establish positive relationships with stakeholders that result in productive support and accomplishment of the goals for which they are accountable and, thus, make a difference in the daily lives of students by enhancing their learning. School administrators need to effectively use positive psychology, basic communication skills, diversity, social intelligence, empathy, vulnerability, outward mindset, and impressions management to build positive and productive relationships with stakeholders. Ultimately, doing so will benefit goal attainment for the responsibilities of school administrators and translate to improving education for all students.

\subsection{Footnotes}

${ }^{1}$ Based in part on Rice, P. \& Bartz, D.E. (2017, February). Integrating diversity with effective group processes and mindset for more productive teams, committees, task forces, and PLCs. Leadership Matters, 18-21.

${ }^{2}$ Based in part on Bartz, D., Mattox, A., Johnson, C., \& Hall, L. (2017, November/ December). Emotional and social intelligence: How "smart" are you? Leadership Matters, 20-23.

${ }^{3}$ Based in part on Bartz, D.E. \& Bartz, D.T. (2017, October). Confidence, vulnerability, and empathy: Friends to managers. International Journal of Business and Social Science, 8(10), 1-6.

${ }^{4}$ Based in part on Bartz, D.E. \& Bartz, D.T. (2017, October). Confidence, vulnerability, and empathy: Friends to managers. International Journal of Business and Social Science, 8(10), 1-6.

${ }^{5}$ Based in part on Rice, P. \& Bartz, D.E. (2017, February). Integrating diversity with effective group processes and mindset for more productive teams, committees, task forces, and PLCs. Leadership Matters, 18-21.

${ }^{6}$ Based in part on Bartz, D. \& Bartz, D.T. (2017). Strengths management, realistic optimism, and impressions management for managers. International Journal of Organizational Theory and Development, 5(1), 1-9.

\subsection{References}

Arbinger Institute. (2016). The outward mindset: Seeing beyond ourselves. Oakland, CA: Berrett-Koehler.

Bartz, D.E. (2017, June). Communication, feedback, and coaching skills for managers to use with staff members during the performance appraisal process. International Journal of Business and Social Science, 8(6), 1-5.

Bartz, D.E. \& Bartz, D.T. (2017, October). Confidence, vulnerability, and empathy: Friends to managers. International Journal of Business and Social Science, 8(10), 1-6.

Bartz, D. \& Bartz, D.T. (2017). Strengths management, realistic optimism, and impressions management for managers. International Journal of Organizational Theory and Development, 5(1), 1-9.

Bartz, D., Mattox, A., Johnson, C., \& Hall, L. (2017, November/ December). Emotional and social intelligence: How "smart" are you? Leadership Matters, 20-23.

Bartz, D., Thompson, K., \& Rice, P. (2017). Managers helping themselves "be their best." International Journal of Management, Business, and Administration, 20(1), 1-8.

Bass, B.M. \& Bass, R. (2008). The Bass handbook of leadership: Theory, research, and managerial applications (4th ed.). New York, NY: Free Press.

Berman, L. \& Bernard, J. (2018). Treating people well. New York, NY: Scribner.

Bloom, P. (2016). Against empathy: The case for rational compassion. New York, NY: HarperCollins Books.

Bolino, M., Klotz, A.C., \& Daniels, D. (2014). The impact of impressions management over time. Journal of Managerial Psychology, 29(3), 1-25.

Brown, B. (2014a, May). Empathy and good managers (pp. 1-5). Retrieved from http://switchandshiftcom/ empathy-and-good-managers 
Brown, B. (2014b, December). What bosses gain by being vulnerable. In Emma Seppala, (Ed.) Retrieved from http://hbr.org/2014/12/what-bosses-gain-by-being-vulnerable

Bryant, A. (2017, October 29). How to be the big boss. New York Times, Business Section, 4.

DeePak, J. (2014, August). Impressions management techniques and tactics. Retrieved from https://www. slideshare.net.529912/impressions-management-techniques-and-tactics

Druskat, V.U. \& Wolff, S.B. (2013). Building the emotional intelligence of groups. Boston, MA: Harvard Business School.

Dweck, S. (2016). Mindset: The new psychology of success. New York, NY: Ballantine Books.

Goffman, E. (1959). The presentation of self in everyday life. New York, NY: Anchor Books.

Goleman, D. (2017). What is empathy? In Empathy (pp. 1-12). Boston, MA: Harvard Business School Publishing Corporation.

Goleman, D. \& Boyatzis, R. (2013). Social intelligence and biology of leadership. In On collaboration. Boston, MA: Harvard Business Review Press.

Grenville-Cleave, B. (2012). Positive psychology. New York, NY: MJF Books.

Haden, J. (2018). The motivation myth. New York, NY: Portfolio/Penguin.

Hersey, P., Blanchard, K.H., \& Johnson, D.E. (2013). Management of organizational behavior. Boston, MA: Pearson.

Holt, S., Marques, J., Hu, J., \& Wood, A. (2017, Winter/Spring). Cultivating empathy: New perspectives on educating business leaders. The Journal of Value-Based Leadership, 10(1), 1-15.

Jacobsen, D. (2013, June 27). The most important job skill for 2020, and how to cultivate it (web blog post). Retrieved from http://globoforce.com/gfblog/2013/the-most-important-job-skill-for-2020-and-how-to-cultivate-it

Kalman, F. (2017, May 24). Vulnerability is a leadership skill, not a weakness. Leadership Development. Retrieved from http://clomedia.com/2017/05/24/vulnerability-is-a-leadership-skill-not-a-weakness

Kaplan, J. \& Marsh, B. (2018). How luck happens. New York, NY: Penguin Random House LLC.

Krznaric, R. (2014). Empathy. New York, NY: Penguin Group.

Langer, E. (2017). Mindfulness in the age of complexity. In Emotional intelligence: Mindfulness (pp. 1-25), Boston, MA: Harvard Business Review Press.

Leary, M.R. \& Kowalski, R.M. (1990). Impressions management: A literature review and two-component model. Psychological Bulletin, 107(1), 34-37.

Lencioni, P. (2002). Five dysfunctions of a team. San Francisco, CA: Jossey-Bass.

Martinuzzi, B. (2009a). The leader as a mensch. San Francisco, CA: Six Seconds Emotional Intelligence Press.

Martinuzzi, B. (2009b). What's empathy got to do with it? (pp. 1-4). Retrieved from https://mindtools.com/ pages/article/newLDR_75.htm

National Policy Board for Educational Administration. (2015, October). Professional Standards for Educational Leaders [Report].

Pink, D.A. (2006). A whole new mind. New York, NY: Penguin Books.

Rice, P. \& Bartz, D.E. (2017, February). Integrating diversity with effective group processes and mindset for more productive teams, committees, task forces, and PLCs. Leadership Matters, 18-21.

Riggio, R. (2014). What is social intelligence: Why does it matter? Psychology Today. Retrieved from psychologytoday.com/blog/cutting-edge-leadership/201407/what-is-social-intelligence-why-does-it-matter

Seligman, M.E.P. (2011). Flourish. New York, NY: ATRIA.

Seligman, M.E.P. (2006). Learned optimism. New York, NY: Vintage Books.

Seligman, M.E.P. (2002). Authentic happiness: Using positive psychology to realize your potential for lasting fulfillment. New York, NY: Free Press.

Seppala, E. (2014, December 11). What bosses gain by being vulnerable. Harvard Business Review. Retrieved from http://hbr.ogr/2014/12/what-bosses-gain-by-being-vulnerable

Seppala, E. (2017). Why compassion is a better managerial tactic than toughness. In Empathy (pp.13-28). Boston, MA: Harvard Business Review Press.

Shellenbarger, S. (2018, March 6). How to gain power at work when you have none. Wall Street Journal, A15.

Stibel, J. (2017, October 23). How to be a great leader: Embrace your ignorance. USA Today, $2 \mathrm{~B}$.

Tredgold, G. (2018, March 5). The abundance approach. Chicago Tribune, Section 5-2, 1.

Zenger, J. \& Folkman, J. (2017). What great listeners actually do. In Empathy (pp. 29-40). Boston, MA: Harvard Business Review Press. 